\title{
AN EXPERIMENTAL STUDY OF SQUARE FOOTING RESTING ON GEO-GRID REINFORCED SAND
}

\author{
Hemantkumar Ronad ${ }^{1}$ \\ ${ }^{I}$ M.Tech in Geotechnical Engg, Department of Civil Engineering, Basaveshwar Engineering College, Bagalkot
}

\begin{abstract}
A series of laboratory model test has been carried out to investigate the bearing capacity of the square footing resting on reinforced sand bed. The geo-grid as a reinforcement material has been used. In the present study an attempt has been made to study the bearing capacity of square footing on sand reinforced bed. The effect of different parameter like the depth of the upper most layer of reinforcement from the base of the model footing $(u)$, for different densities of the sand $(\gamma=1.55,1.65$, and $1.75 \mathrm{gm} / \mathrm{cc})$ the test has been carried out. Three numbers of layers, has been fixed. The test results showed that the beneficial use of geo-grid reinforcement in terms of increasing in the bearing capacity and minimizing the settlement, at an optimum depth of reinforcement, however for the higher density of the soil gives maximum bearing capacity. Therefore, for effective utilization of geo-grid reinforcement, the optimum depth should be $(u=0.33 B)$ which is found to be good agreement with the past researchers, and the foundation soil should be in higher density.
\end{abstract}

Keywords-Sand, direct shear test, reinforced \& unreinforced, geo-grid, bearing capacity.

\section{BACKGROUND}

During the past three decades, results of several studies have been published that relate to the evaluation of the ultimate and allowable bearing capacities of shallow foundations supported by sand reinforced with multi-layered geo-grid. The concept of reinforced soil is based on the existence of tensile strength of reinforcement and soil reinforcement interaction due to frictional, interlocking and adhesion properties. The method of reinforcing soil with layers of individual reinforcements placed horizontally as described here is best attempted in conjunction with fills that are required to support shallow foundations such as footings. The beneficial use of reinforcement materials like metal strips and geosynthetics to increase the bearing capacity of sand has been clearly established.

\section{BEARING CAPACITY THEORY}

\subsection{Terzaghi's Analysis}

An analysis of the condition of complete bearing capacity failure, usually termed general shear failure, can be made by assuming the soil behaves like an ideally plastic material. This concept was first developed by Prandtl and later extended by Terzaghi. He considered a footing of width B and subjected to a loading intensity $\mathrm{q}_{\mathrm{f}}$ to cause failure. The footing is shallow is equal to or less than width B of the footing. The loading soil fails along the composite surface fede $_{1} \mathrm{f}_{1}$. This region is divided into three zones zone 1 , two pairs of zone 2 and two pairs of zone 3 . When the base of the footing sinks into the ground, zone 1 is prevented from undergoing any lateral yield by the fraction and adhesion between the soil and the base of the footing. Thus zone 1 remains in the state of elastic equilibrium and it acts as if it were a part of the footing. Its boundaries $d_{a}$ and $d_{b}$ are assumed as plane surfaces, rising at an angle $\varphi=\varnothing$ with the horizontal zone 2 is called the zone of radial shear these lines are straight while the lines of the other set are the logarithmic spirals with their located at the outer edges of the base of the footing. zone 3 is called the zone of linear shear, and is identical with that for rankines passive state The boundary of zone 3 rise at $(45-\emptyset / 2)$ with the horizontal the failure zones are assumed not to extend above the horizontal plane through ab of the footing .this implies the shear resistance of the soil above the horizontal plane through the base of the footing is neglected, and the soil above this plane is replaced with a surcharge $\mathrm{q}=\gamma \times \mathrm{D}_{\mathrm{f}}$. 


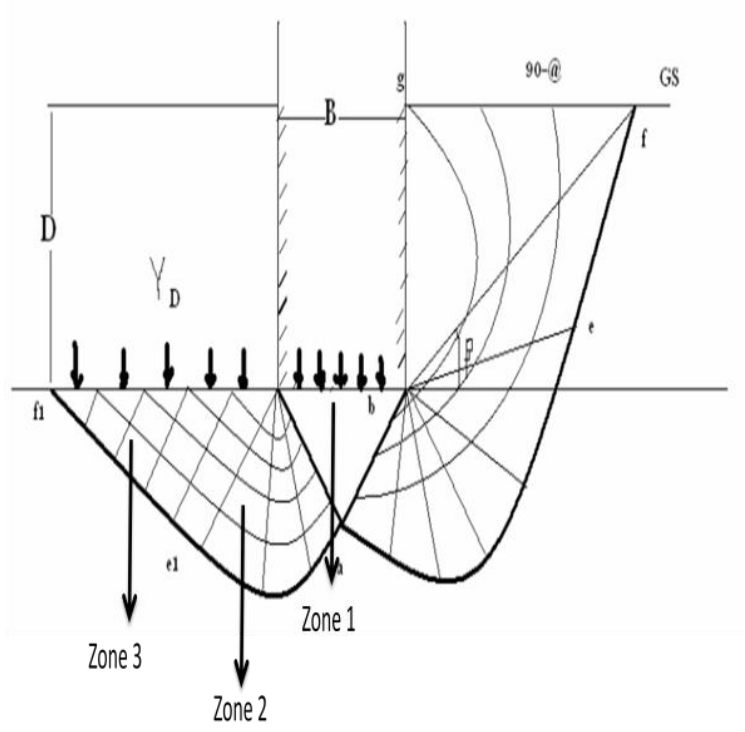

Fig 2.1Terzaghi's theory of shallow foundation

\section{Materials and Experimental Study}

\subsection{Sand}

The medium used in the present study is Krishna river sand, Krishna mandal. The angle of internal friction $(\varnothing)$ obtained from the laboratory direct shear test. The dry unit weight 1.75 $\mathrm{gm} / \mathrm{cc} \&$ Angle of internal friction is $37^{\circ}$.

\subsection{Geosynthetics}

Two types of geosynthetics namely geo-grid (SG-700) were used as the reinforcement material in the sand bed for the model tests.

Table 3.1 Physical properties of Geo-Grid.

\begin{tabular}{|l|l|}
\hline TYPE & SG 700 \\
\hline Tensile strength $\left(\mathrm{KN} / \mathrm{m}^{2}\right) \mathrm{MD}$ & 170 \\
\hline Long term design strength $\left(\mathrm{KN} / \mathrm{m}^{2}\right)$ in Sand & 93.15 \\
\hline Grid Size, Machine Design $(\mathrm{mm})$ & $60 \times 25$ \\
\hline
\end{tabular}

\subsection{Model Footing}

The model square footing used was a hard wooden piece of $150 \mathrm{~mm} \times 150 \mathrm{~mm}$ size and $25 \mathrm{~mm}$ thickness. The base (bottom) of the model footing was made rough by cementing a thin layer of sand to it using epoxy glue.

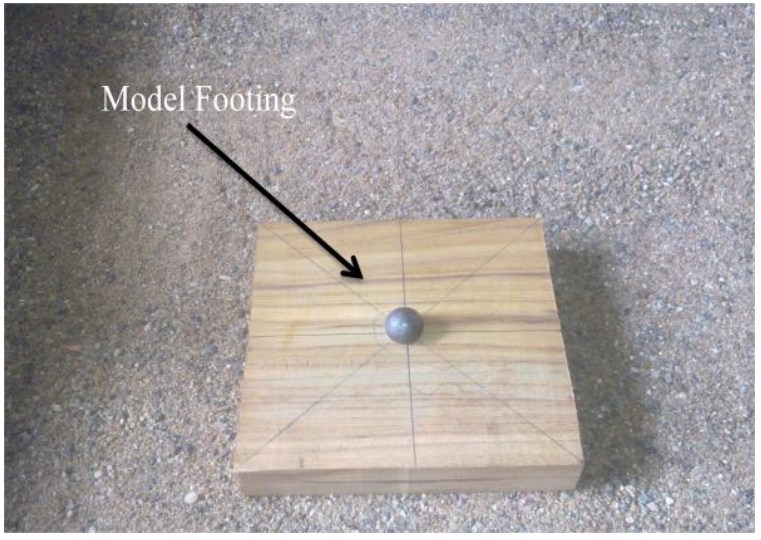

Fig. 3.1 Photographic view of the model footing

\section{EXPERIMENTAL STUDY}

In the present study the model tests were conducted in the laboratory using the wooden box tank which was designed keeping in mind the size of model footing to be tested and the zone of influence. The inside length, width and height of the wooden tank are $600 \mathrm{~mm}, 600 \mathrm{~mm}$ and $600 \mathrm{~mm}$ respectively. The tank was strengthened in horizontal directions using a channel shaped steel section to avoid lateral deformation/bulging of tank walls during filling of the sand bed and during loading conditions. The footing was loaded by a hand operated screw jack supported against a reaction frame. The layout and configuration of the setup is shown in Fig 4.1

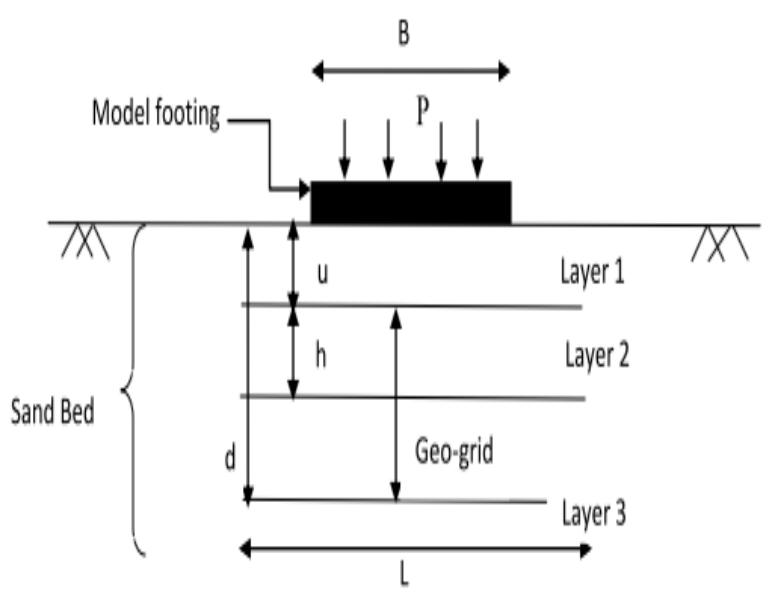

Fig. 4.1 Layout and configuration of planar reinforcement layers in the model tests

\section{RESULT \& DISCUSSION}

In the present study includes observations and discussions of the experiments carried out to examine (i) optimum depth of reinforced zone (ii) density of the soil, checking improvement of bearing capacity (iii) strength improvement ratio (iv) settlement reduction factor. 


\subsection{Un-Reinforced Sand Test for the Square Footing}

The tests results for the unreinforced foundation bed were plotted; the load-deformation curve for the density $1.75 \mathrm{gm} / \mathrm{cc}$, $1.65 \mathrm{gm} / \mathrm{cc}$ and $1.55 \mathrm{gm} / \mathrm{cc}$ are plotted and shown in the Fig. 5.1 .

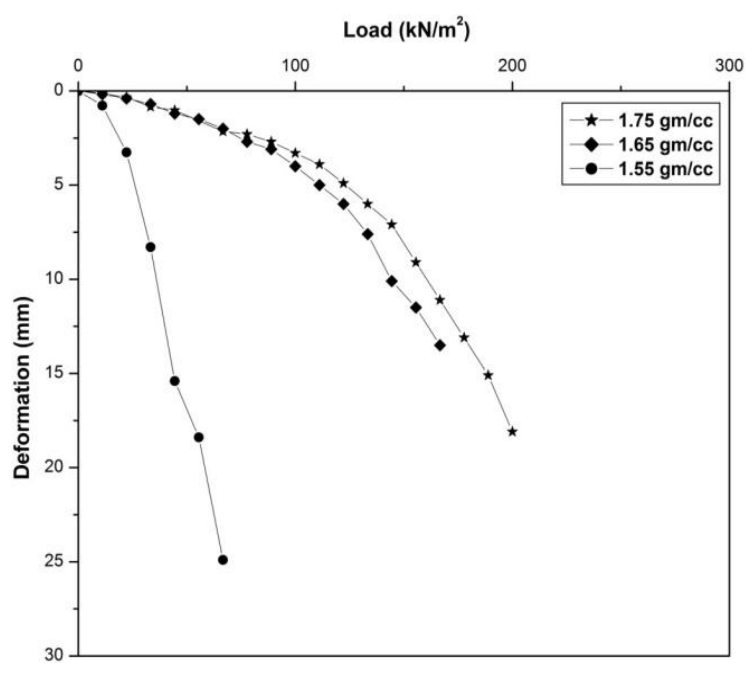

Fig 5.1 Variation of the load with deformation for unreinforced foundation bed

Table 5.1 Ultimate bearing capacity for different density and $\mathrm{u} / \mathrm{B}$ ratio

\begin{tabular}{|c|c|c|c|}
\hline & $\begin{array}{l}\text { Ultimate } \\
\left(\mathrm{kN} / \mathrm{m}^{2}\right)\end{array}$ & bearing & capacity \\
\hline Density & $\begin{array}{l}1.55 \\
\mathrm{gm} / \mathrm{cc}\end{array}$ & $\begin{array}{l}1.65 \\
\mathrm{gm} / \mathrm{cc}\end{array}$ & $\begin{array}{l}1.75 \\
\mathrm{gm} / \mathrm{cc}\end{array}$ \\
\hline $\begin{array}{l}\text { Without } \\
\text { reinforcement }\end{array}$ & 30 & 100 & 106.6 \\
\hline $\begin{array}{l}\text { Type of } \\
\text { reinforcement }\end{array}$ & SG 700 & & \\
\hline $\mathrm{u} / \mathrm{B}=0.16$ & 147.7 & 160.6 & 174.4 \\
\hline $\mathrm{u} / \mathrm{B}=0.33$ & 170.0 & 192.2 & 225.5 \\
\hline $\mathrm{u} / \mathrm{B}=0.66$ & 105.5 & 127.3 & 140.0 \\
\hline
\end{tabular}

\subsection{Effect of U/B on Ultimate Bearing Capacity of the}

\section{Square Footing on Reinforced Sand Bed of (SG 700).}

It can be seen that, the load v/s footing deformation response of reinforced sand bed is far better than the non-reinforced case. This is due to the frictional resistance at the interface of the sand and reinforcement which would have prevented the soil mass from shearing under vertical applied load
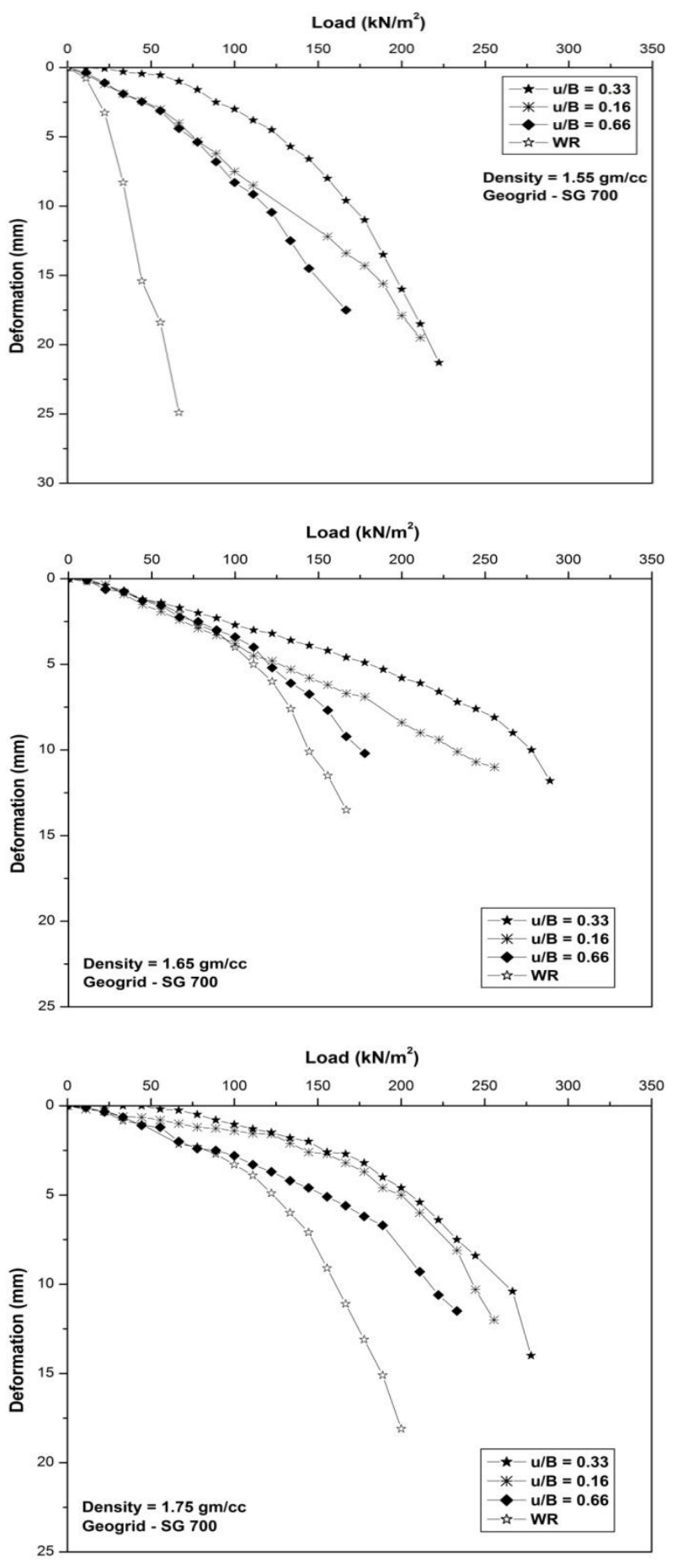

Fig.5.1 For the density $1.55 \mathrm{gm} / \mathrm{cc}, 1.65 \mathrm{gm} / \mathrm{cc}, 1.75 \mathrm{gm} / \mathrm{cc}$ load-deformation curve for $\mathrm{u} / \mathrm{B}=0.16,0.33$ and 0.66 , and unreinforcement for the geo-grid SG 700.

\subsection{Strength Improvement Ratio}

In order to get a quantitative assessment of the extent of soil improvement, the improvement due to the provision of geogrid reinforcement can be shown in non-dimensional strength 
improvement ratio which is define as "the ratio of the ultimate bearing capacity of the reinforced sand to the un-reinforced sand which is same as bearing capacity ratio.

$>$ Calculation of the strength improvement ratio for $\gamma=$ $1.55 \mathrm{gm} / \mathrm{cc}, \mathrm{u} / \mathrm{B}=0.33$ for $\mathrm{SG} 700$

Strength improvement ratio

$$
\begin{gathered}
=\frac{\text { Ultimate bearing capacity of reinforced sand }}{\text { Ultimate bearing capacity of un }- \text { reinforced sand }} \\
\text { Strength improvement ratio }=\frac{170}{30}=5.6
\end{gathered}
$$

Table 5.2 Strength improvement ratio for different density and $\mathrm{u} / \mathrm{B}$ ratio.

\begin{tabular}{|l|l|l|l|}
\hline & \multicolumn{3}{|l|}{ Strength Improvement Ratio } \\
\hline $\begin{array}{l}\text { Type of } \\
\text { reinforcement }\end{array}$ & SG 700 \\
\hline Density & $\begin{array}{l}\mathbf{1 . 5 5} \\
\text { gm/cc }\end{array}$ & $\begin{array}{l}\mathbf{1 . 6 5} \\
\text { gm/cc }\end{array}$ & $\begin{array}{l}\mathbf{1 . 7 5} \\
\text { gm/cc }\end{array}$ \\
\hline $\mathrm{u} / \mathrm{B}=0.16$ & 4.9 & 1.6 & 1.6 \\
\hline $\mathrm{u} / \mathrm{B}=0.33$ & 5.6 & 2.0 & 2.1 \\
\hline $\mathrm{u} / \mathrm{B}=0.66$ & 3.4 & 1.2 & 1.3 \\
\hline
\end{tabular}

\subsection{Settlement Reduction Factor}

The improvement due to the inclusion of a geo-grid reinforcement layer in sand, in terms of reduction in footing settlement, can be known through the parameter settlement reduction factor which is defined as:

$$
\text { Settlement reduction factor }=S_{o}-S_{r} / S_{o}
$$

Where in, $S_{o}$ is the settlement of the non-reinforced sand bed at a given pressure.

$\mathrm{S}_{\mathrm{r}}$ is the settlement of the sand bed strengthened by geo-grid reinforcement at the same pressure.

$>$ Calculation of settlement reduction factor for $\quad \boldsymbol{\gamma}=$ $1.55 \mathrm{gm} / \mathrm{cc}, \mathrm{u} / \mathrm{B}=0.33$ for the geo-grid SG 700 .

$$
\text { Settlement reduction factor }=\frac{5-0.2}{5}=0.96
$$

Table 5.3 Settlement reduction factor for different density and $\mathrm{u} / \mathrm{B}$ ratio

\begin{tabular}{|l|l|l|l|}
\hline & \multicolumn{3}{|c|}{ Settlement Reduction Factor } \\
\hline Density & $\begin{array}{l}\mathbf{1 . 5 5} \\
\text { gm/cc }\end{array}$ & $\begin{array}{l}\mathbf{1 . 6 5} \\
\text { gm/cc }\end{array}$ & $\begin{array}{l}\mathbf{1 . 7 5} \\
\text { gm/cc }\end{array}$ \\
\hline $\begin{array}{l}\text { Without } \\
\text { reinforcement }\end{array}$ & 5 & 3 & 2.3 \\
\hline Type of & SG 700 & \\
\hline
\end{tabular}

\begin{tabular}{|l|l|l|l|}
\hline reinforcement & \multicolumn{3}{|c|}{} \\
\hline $\mathrm{u} / \mathrm{B}=0.16$ & 0.68 & 0.32 & 0.26 \\
\hline $\mathrm{u} / \mathrm{B}=0.33$ & 0.96 & 0.41 & 0.47 \\
\hline $\mathrm{u} / \mathrm{B}=0.66$ & 0.60 & 0.28 & 0.30 \\
\hline
\end{tabular}

Due to the inclusion of geo-grid at a depth of $0.33 \mathrm{~B}$ the bearing capacity increased significantly which is quantified by strength improvement ratio and reduces settlement.

\section{CONCLUDING REMARKS}

$>$ Provision of the geo-grid reinforcement layers improves the load carrying capacity of the model footing.

$>$ Effective depth of the zone reinforcement below a square footing is twice the width of the footing (2B).

$>$ In the case of the geo-grid reinforced both ultimate bearing capacity and bearing capacity at any settlement of square footing are maximum at $\mathrm{u} / \mathrm{B}=0.33$.

$>$ From the overall performance point of the view of the model footing (i.e., both strength and settlement aspects), the optimum location of the geo-grid reinforcement is about $0.33 \mathrm{~B}$ below the base of the footing, within the effective reinforcement zone.

$>$ Strength improvement ratio also increases up to a depth ratio $\mathrm{u} / \mathrm{B}=0.33$, thereafter it decreases with further increases in depth ratio. This is due to the fact the magnitude of the mobilized frictional resistance at the interface of sand and the reinforcement because of the smaller or the lower overburden pressure over the reinforcement.

$>$ Use of the geo-grid reinforcement leads to better performance from the point of view of strength improvement as well as settlement reduction.

$>$ The experimental study results suggest the possibility of developing a predictive model for strength improvement due to use of geo-grid reinforcement.

$>$ As the density of the soil increase the load carrying capacity increases. In order to get the effective utilization of geo-grid reinforcement, the soil should have higher density therefore the stiffness between the soil and geo-grid reinforcement increases.

$>$ The test results showed that there is no much variation when compared with the previous investigators, the variation is within 5 to $10 \%$.

\section{REFERENCES}

[1] Adams, M.T., Collin, J.C., 1997. Large model spread footing load tests on geogrid-reinforced soil foundations. Journal of Geotechnical and Geoenvironmental Engineering, ASCE 123 (1), 66-72.

[2] Gosh, A., Gosh, A., Bera, A.K., 2005. Bearing capacity of square footing on pond ash reinforced with jute geotextiles. Geotextiles and Geomembranes 23 (2), 144-173. 
[3] Huang, C.C., Menq, F.Y., 1997. Deep footing and wide-slab effects on reinforced sandy ground. Journal ofGeotechnic al and Geoenvironmental Engineering, ASCE 123 (1), 30-36.

[4] Hataf, N., Razavi, M.R., 2000. Use of tire shreds for bearing capacity of shallow foundation on sand. In: Proceedings of 3rd International Conference on Ground Improvement Techniques, Singapore, pp. 189194.

[5] Khing, K.H., Das, B.M., Cook, E.E., Yen, S.C., 1993. The bearing capacity of a strip footing on geogrid reinforced sand. Geotextiles and Geomembranes 12, 351-361.

[6] Madhavi Latha, G., and Somwanshi, A.B., 2009(a). Bearing capacity of square footings on geosynthetic reinforced sand. Geotextiles and Geomembranes 27, 281-294.

[7] Patra, C.R., Das, B.M., Atalar, C., 2005. Bearing capacity of embedded strip foundation on geogridreinforced sand. Geotextiles and Geomembranes 23, 454-462.

[8] Madhavi Latha, G., and Somwanshi, A.B., 2009(b). Effect of reinforcement form on the bearing capacity of square footing on sand. Geotextiles and Geomembranes 27, 409-422.

[9] Yetimoglu, T., Wu, J.T.H., Saglamer, A., 1994. Bearing capacity of rectangular footing on geogrid reinforced sand. Journal of Geotechnical Engineering ASCE 120, 2083-2099.

[10] Shin, E.C. and Das, B.M., 2000. Experimental Study of Bearing Capacity of a Strip Foundation on GeogridReinforced Sand, Geosynthetics International, Vol. 7, No. 1, pp. 59-71. 